\title{
Public versus private: the medical resident perspective
}

\author{
Ben Hoyt
}

ß See related articles pages 896 and 901

I $t$ is nothing short of remarkable that the complex issue of health care reform in Canada has been boiled down to a mere 2 words: "private" and "public." Why must opinion be so polarized? Why has the emphasis been drawn away from the myriad shades of grey that lie between a public system and privatization? It is too easy to blame the media for perpetuating divergence in this debate. Although we might feel that the media should do a better job in educating the public about the issues - such as the fundamental difference between private funding and private delivery - this is hardly realistic in today's world of eightsecond sound bites. Besides, controversy and polarization sell newspapers, not educational pieces on health care administration. As health care providers, we are the ones who know the intricacies of the system. We, therefore, should be providing comprehensive input into meaningful reform strategies. Unfortunately, this did not happen at the CMA's annual General Council meeting this August.

During the General Council meeting in Edmonton, the Canadian Association of Internes and Residents (CAIR) put forward a simple motion that called on CMA members to reaffirm its position that health care should be provided on the basis of need rather than wallet size. We also denounced the notion that a private health insurance system would solve our wait-time crisis. The intent of this motion was not to identify a single solution that would fix our system, nor was it to suggest that the status quo is just fine. Rather, it was intended to eliminate one possible solution from consideration, thus allowing the CMA to focus debate on the infinite number of possibilities that exist within the grey zone.

Very early in the discussion, a delegate moved to split our motion. The result was 2 distinct motions: the first simply reaffirming the CMA's commitment to care provision based on need, and the second denouncing the notion of private insurance. As expected, the first of the 2 was passed almost unanimously while the second was defeated by a 2:1 margin. Earlier, delegates approved a motion calling on the CMA to draft a report within 6 months exploring all possibilities with respect to care delivery and funding. Many delegates stated that they could not support the second part of our motion, as it would prevent the working group from exploring the private insurance route. They appeared to feel that all options should be left on the table until more information was available.

In an ironic twist, the delegates took a very different ap- proach the following day. The next controversial motion discussed called on the CMA to support access to private health insurance to cover medically necessary services when the public system fails to meet established benchmarks. The implications of this motion were very clear: those who could afford private insurance would be able to buy access to more timely care, while those who could not afford the insurance would have to continue to wait in the faltering public system. In other words, care should be provided based on wallet size rather than need. Surprisingly, the CMA members voted in favour of this motion by a margin of almost 2:1. I still do not understand how the same group of people can support providing care based on need on a Tuesday, only to suggest on a Wednesday that patients should be able to buy better access to care regardless of need.

The residents attending General Council were congratulated for their efforts. In the same breath, we were told that we were too young, too naive and too idealistic. We were told that we have yet to see what it is like to work in a failing system. Eventually, we would see that the only solution is private insurance. Established physicians are understandably frustrated with the system, but I can't help but disagree with their proposed solution.

Like most physicians in this country, Canadian medical residents feel strongly that something needs to change. The current system is failing to provide timely access to care and is not going to improve without major reforms that go far beyond repeated infusions of federal cash. But why must we scrap a fundamental Canadian value - equal access to care for all - in the process? Why can't we revamp our system within the confines of public funding? Critics suggest that the expenses are overwhelming. Perhaps we need to do a better job of controlling costs, improving our efficiency and preventing disease. They also suggest that our revenue pool has run dry. Perhaps we need to find innovative sources of revenue. The publicly funded system has survived for nearly 50 years; there must be room for innovative improvements that will allow it to last at least another 50.

Within the confines of our current medicare system, there are likely a number of ways that expenses can be minimized. First and foremost, we need to prevent disease and relieve some of the burden facing our system. Population-wide health promotion strategies should be first and foremost in any reform plan. Second, there may be room for government regulation of some health-related indus- 
tries. Why should a pair of hospital tweezers cost many times more than a pair of cosmetic ones? Perhaps there is a role for some government regulation of the price of health equipment and supplies in Canada. Finally, we need a plan to make more efficient use of our current infrastructure. It makes no sense to have diagnostic imaging wait lists that are months long when some of our equipment sits idle from suppertime until the following morning. Although there would be staffing costs associated with running these machines for longer hours, it would likely be cheaper than buying a second or third MRI in some centres to tackle the long waits.

Finding new revenue is obviously very challenging. Provinces already spend nearly half their budgets on health, and the public clearly pays enough taxes. That being said, perhaps we need to create revenues from areas that are directly related to the poor health of some Canadians. If we recognize that obesity, tobacco and alcohol are major contributors to our population's health burden, then perhaps we need to increases taxes on fatty foods, cigarettes and liquor and allocate $100 \%$ of these revenues to health spending.

Despite what some may think, Canadian medical residents are not all simply naive and idealistic. We are a group of young physicians who believe strongly that no Canadian should be classed higher or lower than another when it comes to access to health care. What's more, nearly every survey and report on Canadian health care published over the last 10 years shows that the Canadian public agrees with our position. We are not asking anyone to maintain the status quo, we are simply calling on all 3 levels of government to make effective, efficient and responsible reforms that will allow all Canadians to have equal access to high quality care for generations to come.

Dr. Hoyt is President of the Canadian Association of Internes and Residents, Ottawa, Ont.

Correspondence to: bjahoyt@dal.ca

\section{Clinical trial registration}

CMAJ will consider clinical trials for publication only if they have been registered in a publicly accessible clinical trials registry before the enrolment of the first patient. The criteria for acceptable registration are described in CMAJ (2005; 172 [13]:1700-2). 